\title{
Does Autonomy Really Matter in Language Learning?
}

\author{
Gülnihal Şakrak-Ekin \\ Akdeniz University \\ Correspondence concerning this article should be addressed to Gülnihal Şakrak-Ekin, Dumlupınar Bulvarı, \\ Akdeniz Üniversitesi, Yabancı Diller Yüksekokulu, Kat:2 Oda:3 Merkez Kampus, 07058, Antalya, Turkey. \\ E-mail: gulnihalsakrak@gmail.com
}

\author{
Cem Balçıkanlı \\ Gazi University
}

\begin{abstract}
Correspondence concerning this article should be addressed to Cem Balçıkanlı, Education Faculty, Department of English Language, Teaching, Gazi University Rektörlügü Teknik okulları, 06560 Yenimahalle/ Ankara, Turkey.E-mail: balcikanli@gmail.com
\end{abstract}

\begin{abstract}
The main aim of this study was to unravel the possible relationship between individuals' level of autonomy as EFL learners and academic success in terms of language learning at the tertiary level. Additionally, this quantitative study focused on exploring EFL learners' level of autonomy and also the relationship between learner autonomy and some personal factors, including gender, age, English level, and the length of English education. In order to assess the participants' levels of autonomy, a questionnaire consisting of 66 items was administered to 267 university students, who were Turkish-speakers of English as a foreign language. The findings showed that more than half of the learners (65.2\%) had a high autonomy level with a mean autonomy score of 461.37 out of 660. As for the personal variables, only gender was found to be a significant factor in regards to learners' autonomy, in this case, in favour of females. Correlation analysis revealed a positive correlation between learner autonomy level and the academic success of language learners. In other words, the academic success of language learners increased with their autonomy and vice versa. In accordance with the literature, the present study revealed that learner autonomy could be considered one of the factors that affects the success of language learners. Based on the findings, it might be suggested that learner autonomy and possible ways to promote it in and out of class should be given more importance. Further empirical research was suggested in order to comprehend unexplored aspects of learner autonomy in language learning.
\end{abstract}

Keywords: learner autonomy; language proficiency; academic success/performance; EFL students; foreign language learning

\section{Introduction}

Toward the end of the 20th century, significant changes emerged as a result of social, technological, and economic improvements. Personal computers, the internet, mobile phones, etc. might be listed as some of the leading changes affecting almost all of the study areas. As a result, an information explosion has emerged and made the concept of lifelong learning necessary for individuals. In order for people to be able to handle all the information coming from different channels, they need to take responsibility for their own learning (Benson, 2001). In addition, more attention has been given to learner autonomy all around the globe due to the paradigm shift from a teachercentred to a learner-centred approach (Balçıkanll, 2010; Benson, 2001; Borg \& Al-Busaidi, 2012; Ertürk, 2016; Lee, 2016; Little, 2007, 2017; Liu, 2012). The number of studies with different standpoints related to autonomy has been increasing rapidly. Researchers have focused on autonomy training (Dam, 2003; Little, 1995), language learning strategies (Oxford, 1999), curriculum (Cotterall, 2000), textbooks (Reinders \& Balçıanlı, 2011), online tools (Lee, 2016; Sanprasert, 2010; Reinders, 2006), and teachers' beliefs and attitudes (Borg \& Al-Busaidi, 2012) in order to foster autonomy. Meanwhile, other researchers have explored the variables that might affect learner autonomy such as gender (Naeeini, Riazi \& Salehi, 2012; Üstünlüoğlu, 2009; Zhao \& Chen, 2014), proficiency (English) level (Dafei, 2007; Zarei \& Zarei, 2015), length of education (Tuo \& Xia, 2017), and academic success (Lowe, 2009; Ng, Confessore, Yusoff, Abdul Aziz \& Lajis, 2011; Tilfarlioglu \& Ciftci, 2011; Yen \& Lui, 2009).

Among all these constructs, it has been asserted that there is a positive relationship between learners' level of 
autonomy and their academic success (Lowe, 2009; Ng, Confessore, \& Abdullah, 2012; Yen \& Liu, 2009). There are a number of studies that highlight learner autonomy and its relation with the aforementioned constructs; however, there have been limited deliberate attempts to examine the relationship between learner autonomy and language proficiency (Alrabai, 2017; Dafei, 2007; Ghorbandordinejad \& Ahmadabad, 2016; Liu, 2012; Myartawan, Latief, \& Suharmanto, 2013). In the field of language learning and teaching, students are expected to become more involved in the language learning process. As Little (2002) points out, for learners who are not aware of their responsibilities, and are unwilling to take responsibility for their own learning, it is troublesome to reflect on their own learning process critically.

Dafei (2007) states that students' English proficiency is significantly and positively related to their learner autonomy and the more autonomous learners become, the more likely they achieve high language proficiency. However, while Dafei (2007) points out the intimate relationship between autonomy and language learning, this relationship has mostly been examined on a theoretical level and there is a need for empirical research. Thus, the present study aimed to explore language learners' levels of autonomy and the variables that might affect learners' autonomy, including gender, age, English level, and the length of English education. Additionally, the current study focused on investigating the possible relationship between autonomy and English proficiency as higher levels of autonomy are generally associated with effective learning and it is believed that learners with higher levels of autonomy tend to be more successful in language learning than those who are less autonomous.

\section{Learner Autonomy}

The importance of autonomy became evident after the Council of Europe's Modern Languages Project was established in 1971. Thanks to this project, the concept of autonomy entered the field of language education. One of the most important outcomes of this project was the Centre de Recherches et d' Applications en Langues (CRAPEL), which turned into an excellent source of research and helped the concept of autonomy become more recognizable (Holec, 1981). Different scholars and researchers have defined autonomy according to their own perspective. For example, while Holec $(1981$, p. 3) defines autonomy as "the ability to take charge of one's own learning", Benson (2001, p. 47) states that autonomy is "the capacity to take control over one's own learning". Another definition belongs to Little (1999, p. 4), who believes that autonomy is "a capacity - for detachment, critical reflection, decision-making, and independent action". One can come across several definitions of learner autonomy in the literature; however, it can be seen that all of them share a common ground, which is: "knowledge is something built by the learner" (Candy, 1991, p. 207). Little (1991, p. 3) suggests that there has been a tendency to misunderstand the concept since it might be considered "synonymous with self-instruction or a new methodology". Little (1991, p. 3) also emphasizes that autonomy does not mean that "autonomous learners make the teachers redundant". In line with Little's ideas, Holec (1981) pinpoints that autonomy is not a kind of approach but a learning goal.

The main reason that autonomy has attracted so much attention in various cultures is because it promotes motivation and, as a result, it ensures the effectiveness of learning (Bhattacharya \& Chauhan, 2010; Liu, 2012; Sanprasert, 2010). Autonomy plays a key role in language learning because autonomous learners find ways to overcome issues that could lead to diminishing their motivation. Moreover, Little (2003) argues that effective communication is based on complex skills that can be acquired through use, and learners who reveal social autonomy in their learning environment will be more successful communicators. Similarly, other researchers have emphasized that academic success in foreign language learning depends on students developing some amount of autonomy (Benson \& Huang, 2008; Dam \& Legenhausen, 2010). In EFL (English as a foreign language) contexts like Turkey where language learning mainly takes place in the classroom and learners lack opportunities to practice the target language outside the classroom, it is a demanding task to keep students' motivation high (Ho, 1998; Liu, 2012; Tilfarlioglu \& Ciftci, 2011).

Although the question whether autonomy can be measured or not has been a controversial issue among researchers (Benson, 2010; Dam \& Legenhausen, 2010; Lamb, 2010), Benson (2010) highlights that the most prominent problem regarding measuring autonomy is defining its observable components. As discussed in the literature, the multidimensionality of autonomy (Benson, 2001), the nature of autonomy as a capacity (Confessore \& Park, 2004), and the developmental process of autonomy (Little, 1991) are other problematic issues that stem from the difficulties observing the components of autonomy. In spite of these difficulties, Benson (2010, p. 95) argues that autonomy can be "a testable construct in foreign language education contexts in the sense that it can reasonably be reduced to measurable behaviours in which control over aspects of the language learning process are 
displayed". It has also been suggested in the literature that learners' level of autonomy is highly associated with the culture to which they belong. For instance, Chan (2001) claims that in some cultures including China, Japan, and Turkey, promoting learner autonomy can be harder than in Western cultures because the former are part of an exam-oriented and competitive educational system that diminishes teachers' power to include autonomy-raising activities in the class.

In the Turkish EFL context, the findings on levels of learner autonomy have been controversial. Dokuz (2009) suggests that learners in Turkey have a positive attitude toward autonomy and they could be defined as autonomous learners as they are eager to take risks to learn what is asked for them to learn on their own. This result might be seen as unexpected because Yumuk (2002) and Sert (2006) suggest that in Turkish classrooms, the teachers' role does not allow students to be autonomous, and as traditional education methods are common students are seen as passive listeners. Moreover, they state that no significant steps are being undertaken to promote learner autonomy within and beyond the classroom. Accordingly, Turkish students could be considered to have a low level of autonomy. Nonetheless, more recent studies have emphasized the fact that Turkish students have positive attitudes towards learner autonomy (İmre, 2015; Ünal, Çeliköz \& Sarı, 2017) and that language learners are open to being autonomous and willing to study actively and independently under guidance (Olur, 2013), which can be accepted as signs of change. In order to overcome the inconsistency among the various research findings, we felt the need to have a closer look at the level of autonomy of Turkish EFL learners. Olur (2013) conducted a study to investigate 98 high school students' awareness of learner autonomy by focusing on aspects such as learner roles, responsibilities, and reasons for language learning and concluded that high school students are open to being autonomous but under guidance; in other words, the participants were generally willing to study actively and independently but the responsibility section showed that they mostly expected to be directed or controlled by their teachers.

As the findings of previous studies conducted in the Turkish context are controversial, factors including gender, age, length of education, and language proficiency were included in the present study so as to comprehend the effect of these variables and the concept of learner autonomy better. Among these variables, gender has been the most popular one. In some previous studies, gender has not been found to be a significant factor on learner autonomy (Naeeini et al., 2012; Tuo \& Xia, 2017). However, according to the findings of several other studies, gender seems to be an important variable in autonomy and some differences between male and female students have been put forward in favour of females. That is to say, female learners were found to be more autonomous than male learners (Lowe, 2009; Varol \& Yllmaz, 2010; Zhao \& Chen, 2014). Another variable included in the present study was age because there are no research studies focusing the effects of age as a variable on learner autonomy. By including this variable, the researchers of the present study aimed to find out whether older students or younger ones display better levels of autonomy. The findings of the present study related to age can give us some clues about which age group might be more oriented toward autonomy in classroom activities. According to Benson (2001, p. 59), individuals are born self-directed learners, yet cultural factors including child-raising styles and the school system might affect the development of learner autonomy (Boyno, 2011). In the same vein, Thomson (1996) highlighted that autonomy is part of human nature and toddlers take control of learning their mother tongue; however, as learning becomes more complicated, the school system intervenes and teenagers or adults tend to avoid self-directed learning and are in favour of being directed by teachers and teaching materials. By adding the third variable the length of education in the present study, the researchers aimed to discover if early starters to language learning might have a higher level of autonomy. Tuo and Xia (2017) reported that the longer the educational experience is, the higher the level of autonomous learning awareness and behaviour. As for the last variable, the English level of learners was also included in the present study since there have been mismatches among the findings of studies regarding the effect of learners' level of English on their autonomy. For instance, Dafei (2007) and Myartawan et al. (2013) suggested learners' level of English positively correlates with their autonomy; that is to say, students with a higher levels of autonomy benefitted in terms of having a higher English level. On the other hand, Zarei and Zarei (2015) reported that the language level of students is not an influential factor for either their autonomy or motivation.

\section{Academic Success}

'Success' is a wide-ranging concept because it embraces various aspects of life including relationship success, job success, and academic success. Additionally, success is also flexible because its measures and criteria can be very subjective. When language proficiency is considered a form of success, it is hard to conceptualize. In previous studies, some researchers have tried to define language proficiency. For instance, Solórzano (2008) argues that 
language proficiency can be defined as structural proficiency, mastery of discrete language elements, or functional proficiency, being able to use appropriate language in a specific social context. Furthermore, Cummins (2008) defines language proficiency in two different ways: the first one is social language proficiency, which refers to the skills required in social contexts; and the second one, academic language proficiency, which is oral and written abilities students use at school. Regardless of which definition of language proficiency is chosen, the aim of English instructors is to help their students become proficient users of the target language or basically to be successful in language learning.

Lavin (cited in Lowe, 2009, p.18) provides a useful definition of the term academic performance and briefly describes it as "some method of expressing a student's scholastic standing and usually this is a grade for a course, an average for a group of courses in a subject area, or an average for all courses expressed on a 0-to-100 or other quantitative scale". Although there are several ways to evaluate academic success, grades and grade point averages (GPA) measures are the most common tools as they are readily available assessments for institutions and they enable us to measure the accomplishment of learning objectives as well as the acquisition of skills and competencies (York, Gibson \& Rankin, 2015). Benson (2010) highlights the difficulty in evaluating a learner's proficiency by means of tests since language proficiency is a multidimensional construct.

It is clear that being successful in language learning is a complex task that is related to numerous factors such as strategy use (Oxford, 1989), affective factors (Gardner \& MacIntyre, 1993), and individual differences (Dörnyei \& Ryan, 2015). Oxford (1999, p. 120) emphasizes that the real challenge regarding language learning is "to help create more effective language learners who will be able to use their new languages for actual communication". Therefore, strategy use, language proficiency, and learner autonomy must work together to meet this challenge. Oxford (1999, p. 111) also claims that autonomy leads to greater success or proficiency and summarizes the situation by using "five A's", "Ability, Attitude + Action = Autonomy $\rightarrow$ Achievement". Once the previous studies focusing on learners' autonomy and success were taken into consideration, it was found that the correlation between academic success and learner autonomy is positive and linear, which suggests that the academic success of language learners increased with their autonomy and vice versa (Alrabai, 2017; Tilfarlioglu \& Ciftci, 2011; Tuo \& Xia, 2017; Yen \& Liu, 2009). For instance, Lowe (2009) investigated the correlation between learner autonomy as measured by the Learner Autonomy Profile-Short Form (LAP-SF) and academic performance measured by GPA. The results of Lowe's study revealed that there is a positive, significant correlation between the LAP-SF total score and total GPA, indicating a significant relationship between learner autonomy and academic performance. Another study exploring the relationship between learner autonomy and final grades was carried out by Yen and Lui (2009) and the results suggest that learner autonomy is a valid predictor of course success and final grades in community college online courses.

In addition to the aforementioned studies that focused on students' general success, some of the researchers attempt to figure out the relationship between learner autonomy and language proficiency in terms of academic success. In the Indonesian cultural context, Myartawan et al. (2013) investigated the correlation between learner autonomy, self-efficacy, and English proficiency. The sample consisted of 120 Balinese university students. The data analysis revealed that learner autonomy and English proficiency have a significant, strong, positive relationship. In other words, it seems that students with a higher level of autonomy also have a higher level of language proficiency in English. In the Turkish EFL context, Tilfarlioglu and Ciftci (2011) investigated the relationship among self-efficacy, learner autonomy, and academic success among 250 preparatory school students from five different universities. They confirmed a strong link between learner autonomy and language proficiency; that is to say, more autonomous learners become more successful in the process of language learning. From the studies described above, it is apparent that a relationship exists between learner autonomy and academic performance of language learners, yet there is a limited number of research studies focusing on this relationship in the Turkish EFL context. Thus, the aim of the present study is to contribute to a deeper understanding of learner autonomy by providing insights into its relationship with academic success regarding language proficiency and with some personal factors including age, gender, the length of English education, and English level. In line with the purposes of this study, the following questions guided the research:

1. What is the level of autonomy of Turkish EFL learners at the tertiary level?

2. Is there a statistically significant relationship between some personal factors-including age, gender, the length of English education and English level- and the learners' level of autonomy?

3. What is the relationship between learner autonomy and the academic performance of Turkish EFL learners regarding language proficiency? 


\section{Methodology}

\section{Research Context and Participants}

The study took place in the School of Foreign Languages of a Turkish medium state university in the southern part of Turkey. For most of the departments and faculties, including architecture, engineering, medicine, and civil aviation, it is compulsory to complete a one-year preparatory program in which the students only focus on language learning before taking departmental courses. The School of Foreign Languages administers a placement test for all newly accepted first year students at the beginning of the academic year, and approximately 1,250 students enrol in the preparatory program each year. According to their preferences or the expectations of the students' departments, the students can take the test in one of these languages: English, German, or French. In the test, the students who score 60 points or more start their departmental courses, and those who score lower than 60 points are expected to complete a one-year intensive language program in the language of their choice.

The course content of the School of Foreign Languages aims to help students acquire English language proficiency for their undergraduate studies. To reach this aim, a general course book and some supplementary materials for each skill (reading, writing, listening, and speaking) are utilized by the instructors. Communicative language teaching methodology was adopted and the course book was selected with this in mind. Although students are encouraged to take responsibility for their learning process by using project work and portfolios, there is no explicit training promoting learner autonomy. Learners need to complete 800 hours of English classes and accomplish descriptors for each level (A1-breakthrough, A2-waystage, and B1-threshold) according to the Common European Framework of Reference for Languages (CEFR). For instance, an A2 level learner is expected to understand short, simple texts containing the highest frequency vocabulary, including a proportion of shared international vocabulary items; and identify specific information in simple written material such as letters, brochures, and short newspaper or online articles according to the reading descriptor of this level.

The aim of the study, participation terms, and issues related to withdrawal were explained to all the classes personally by one of the researchers. A sample of 267 volunteered university students who were taking one-year intensive English courses participated in the study through convenience sampling. The ease of this sampling technique was the principal reason for this selection. Even though nearly 30 classes, which included nearly 500 students, showed interest in the study, $20 \%$ of them did not consent to share their GPA. In addition, almost $10 \%$ of the questionnaires were eliminated due to missing information. Furthermore, 20 of the students could not complete the course because of attendance problems and they were not allowed to take the final exam. After all of the eliminations, 267 students from 16 different classes were accepted as participants. Their ages ranged between 17 and $29(\mathrm{SD}=1.25)$ with a mean of 19.3. According to the CEFR, the students were placed into A1 (breakthrough), A2 (waystage), and B1 (threshold) level classes. Details of the participants' demographic information are presented in Table 1.

Table 1

Demographic Information of the Participants $(N=267)$

\begin{tabular}{|c|c|c|c|}
\hline Variable & & Frequency & Percentage \\
\hline \multirow{2}{*}{ Gender } & Male & 124 & 46.4 \\
\hline & Female & 143 & 53.6 \\
\hline \multirow{3}{*}{ English Level } & A1 & 130 & 48.7 \\
\hline & A2 & 63 & 23.6 \\
\hline & B1 & 74 & 27.7 \\
\hline \multirow{3}{*}{ Length of English Education } & $1-5$ years & 30 & 11.3 \\
\hline & 6 - 10 years & 222 & 83.1 \\
\hline & $11-15$ years & 15 & 5.6 \\
\hline
\end{tabular}




\section{Instruments}

Two data collection instruments were used in the current study. The first one is a questionnaire, the Learner Autonomy Profile-Short Form (LAP-SF), which aims to assess individuals' level of autonomy as learners. By keeping the previous discussions related to the measurability of learner autonomy in mind, we selected the short form of the learner Autonomy Profile (LAP) (Carr, 1999; Derrick, 2001; Meyer, 2001; Ponton, 1999) as a data collection instrument, as it is a battery tool that assesses different aspects of autonomy (desire, resourcefulness, initiative, and persistence) by using four separate Likert-type scales and provides a total autonomy score for each learner. The long form of the LAP was used to extract 66 items by its creators to develop the short form in order to increase the likelihood of high concurrent validity. Confessore and Park (2004) consider the LAP-SF a sufficient tool to make an initial assessment of each respondent's learner autonomy profile. The validity of the LAP-SF was tested with the sample of 1340 respondents and high Cronbach's alpha values and significant inter-correlations were found between subscales (Yen \& Liu, 2009). The LAP-SF consists of 66 items arranged in the Likert-type scale from zero (never perform the behaviour) to ten (always perform the behaviour). Similar to the long version of the LAP, the LAP-SF includes four main constructs: desire, resourcefulness, initiative, and persistence. Briefly, desire describes an individual's motivation to participate in a learning experience, while resourcefulness means a learner's intention to be resourceful. The third component, initiative, describes a person's willingness to initiate learning and the last one, persistence, describes a person's intention to continue learning activities. Confessore (2000) states that when four of the components come together, they achieve an accurate assessment of individuals' autonomous behaviors.

In the present study, a total score on the LAP-SF was utilized in order to evaluate individuals' level of autonomy as learners. A higher total score on the LAP-SF is accepted as the learners having a high level of learner autonomy. Prior to the actual administration of the questionnaire, a pilot study was conducted with a group of 40 preparatory school students from different levels and based on their feedback on the questionnaire, it was turned into a more reader-friendly format and the wording of some confusing items was revised. In previous studies, the Cronbach's alpha coefficients ranged from 0.88 to 0.93 (Confessore \& Park, 2004). For this study, the Cronbach's alpha coefficient of the LAP-SF was reported as .92, which can be defined as a high value as it is over .70. At the end of the questionnaire, a small personal data section was included to get information about the participants' gender, age, English level, and length of learning English.

In this article, success is studied in the form of academic success in language proficiency since all the participants were first-year university students who were taking one-year intensive English instruction. Thus, the terms academic success/performance and language proficiency have been used interchangeably. Even though there are different uses and definitions of success in the literature, in the present study, we used academic performance and language proficiency to refer to the students' academic success in language learning, which was represented by GPA. As the second data source, the GPAs of the students were requested from the student affairs office to evaluate the participants' success in language learning. An explanation part at the beginning of the questionnaire and the personal information part were prepared in the native language of the participants (Turkish) in order to avoid any misunderstandings. For both data collection sources, permission from the participants and the School of Foreign Languages was received before the data collection procedure. At the beginning of the semester, a consent form was taken from each of the participants to obtain and use their GPA for the present study.

The participants' academic success related to language proficiency is represented by their GPA that they obtained from the average of four progress tests and a final test in that specific semester during which the study was conducted. In order to ensure the reliability and validity of the tests during the semester, questions that belong to the International English Language Testing System (IELTS) were utilized in the four progress tests and the final test. IELTS was developed by language experts and has been accepted as one of the most reputable tests to assess the language proficiency of those who want to work or study in an English-speaking context. In the general version of the IELTS tests, the four English skills (listening, reading, writing, and speaking) are assessed. According to the IELTS homepage, the Cronbach's alpha values of the reading and listening tests are estimated 0.88 . Benson (2010) emphasizes the necessity of capturing all of the dimensions of foreign language proficiency and that is why both the final test and the progress tests were included to estimate the students' GPA. In the present study, the participants' GPA was calculated by averaging the $40 \%$ of the progress test results and $60 \%$ of the final test. Accordingly, it was assumed that the students' GPA reflected the overall language proficiency of the students. 


\section{Data Collection and Analysis}

In this quantitative study, one of the researchers visited all the classes in the data collection process and informed preparatory program students about the study. The classes in which all of the students volunteered were selected into the participant group since the LAP-SF was going to be administered during the English lessons at the end of the spring semester. Under normal circumstances, the LAP-SF is administered online but most of the students in the preparatory classes do not have computer access outside the campus; consequently, the researchers preferred to administer a paper-pen form of the questionnaire. During the administration of the questionnaire to all levels, the first researcher was in the class in order to answer questions and prevent possible misunderstandings.

All the tests that were used to calculate students GPAs were administered during the spring semester two months apart. Moreover, the final test was administered two weeks after spring term ended. In both the progress tests and the final test, four language skills were tested by using IELTS question types including matching headings with paragraphs, multiple choice, true/false, summary completion, sentence completion, table completion, and for writing the students were asked to write a letter or a report based on a chart.

In this correlational study, both descriptive and inferential analyses were conducted to shed light on the relationship between the individuals' level of autonomy as learners and their language proficiency. Prior to any type of analysis, the data were firstly screened for several characteristics such as missing data, influential outliers, and normality. After eliminating the missing data and correcting outliers, we conducted KolmogorovSmirnov and Shapiro-Wilk tests to understand whether the data were normally distributed or not. As Table 2 shows, both the autonomy scores and the GPA of the participants were normally distributed $(p>0.05)$; therefore, parametric tests were conducted in the following phases of the study.

Table 2

Tests of Normality

\begin{tabular}{llccccccc}
\hline & \multicolumn{3}{c}{ Kolmogorov-Smirnov } & \multicolumn{3}{c}{ Shapiro-Wilk } \\
\cline { 2 - 8 } & \multicolumn{2}{r}{ Statistic } & df & Sig. & Statistic & df & Sig. \\
\hline Autonomy & .042 & 267 & .200 & .988 & 267 & .022 \\
GPA & .060 & 267 & .020 & .992 & 267 & .167 \\
\hline
\end{tabular}

Secondly, descriptive statistics such as frequencies, percentages, means, and standard deviations were provided in order to describe the participants' characteristics. The individuals' level of autonomy as learners was defined by minimum and maximum autonomy scores. Moreover, independent t-tests and one-way ANOVA tests were applied to investigate the relationship between different personal variables and learner autonomy. As for the relationship between learner autonomy and student success, a Pearson Correlation Coefficient analysis was conducted. All of the statistical computations were carried out by using the IBM SPSS Statistics 20 software program.

\section{Results}

\section{The Average Level of Autonomy of Turkish EFL Learners at Tertiary Level}

In order to explore the students' level of autonomy, first, the overall mean for the 267 participants' LAP-SF score was computed. In the LAP-SF, the lowest possible score was 0 (zero) and the highest possible score was 660. In the present study, the minimum and maximum scores found were 237 and 624, respectively. Additionally, the mean of the learner autonomy scores was found to be $461.37(\mathrm{SD}=62.150)$. If we take the maximum score into consideration, it can be said that 461.37 was a relatively high score. After analysing the means, we divided the scores of the LAP-SF into three groups in order to quantify the learners' autonomous behaviour by considering the minimum and maximum scores of the LAP-SF. 
Table 3

Autonomy Level Groups

\begin{tabular}{llcccc}
\hline & Frequency & Percent & Valid Percent & Cum. Percent \\
\hline Valid & Low Autonomy & 0 & 0 & 0 & 0 \\
& Moderate Autonomy & 93 & 34.8 & 34.8 & 34.8 \\
& High Autonomy & 174 & 65.2 & 65.2 & 100.0 \\
& Total & 267 & 100.0 & 100.0 & \\
\hline
\end{tabular}

As presented in Table 3, the students with scores above 441 were categorized as having a high autonomy level; the learners with scores from 221 to 440 were identified as having a moderate autonomy level while the ones with scores below 221 were considered having a low autonomy level. Among the participants, none of them was categorized as having low autonomy, 34.8\% of the participants were in the moderately autonomous group and $65.2 \%$ of the participants were in the highly autonomous group. In other words, based on the LAP-SF scores, the majority of the Turkish EFL learners were found to be highly autonomous.

\section{Learner Autonomy and Personal Factors}

To investigate the relationship between some personal factors and learner autonomy, independent t-tests and one-way ANOVA techniques were applied, and the findings are presented respectively in the following sections.

Gender. As Table 4 reveals, gender seems to be an important factor for autonomy. There is a significant relationship between learner autonomy and gender in the present study.

Table 4

Gender and Learner Autonomy

\begin{tabular}{llllcr}
\hline Learner Autonomy & Gender & N & Mean & Std. Deviation & Std. Error Mean \\
\hline \multirow{2}{*}{ Autonomy } & Female & 143 & 470.10 & 63.527 & 5.312 \\
& Male & 124 & 451.29 & 59.187 & 5.315 \\
\hline
\end{tabular}

After analysing the data, it was found out that the female participants, with a mean score of 470 , were more autonomous than the male participants with a mean score of 451. A t-test was performed to determine whether gender variable created a difference regarding learner autonomy and there was a significant difference between the autonomy scores of female and male participants: $t(265)=2,491, p=0,013$. It can be seen that the female students outperformed the male students in autonomy scores.

Age. Another variable in the present study was age. According to the results of the one-way ANOVA presented in Table 5, the participants' level of autonomy did not seem to be related to their age.

Table 5

Age and Learner Autonomy

\begin{tabular}{lccccc}
\hline Learner Autonomy & Sum of Squares & df & Mean Square & F & Sig. \\
\hline Between Groups & 65220.011 & 10 & 6522.001 & 1735 & .073 \\
Within Groups & 962238.019 & 256 & 3758.742 & & \\
Total & 1027458.030 & 266 & & & \\
\hline
\end{tabular}

This finding may stem from the fact that nearly $95 \%$ of the participants were between the ages 18 and 20 . That is to say, there were too many students in the same age group, and this made it difficult to reach a comprehensible conclusion. This could be considered one of the constraints of the study.

Length of English education. Length of English education was the third independent variable in the present study. Table 6 shows whether the learners' level of autonomy changes according to how long they have studied English. 
Table 6

Length of Education and Learner Autonomy

\begin{tabular}{lccccc}
\hline Learner Autonomy & Sum of Squares & df & Mean Square & F & Sig. \\
\hline Between Groups & 29259.262 & 13 & 2250.712 & .570 & .877 \\
Within Groups & 998198.767 & 253 & 3945.449 & & \\
Total & 1027458.029 & 266 & & & \\
\hline
\end{tabular}

The results indicated that the students' length of English education had no impact on their autonomy. The fact that most of the participants had been studying English for many years and they were now in the same group might prevent differences in findings related to the length of studying English.

English level. The last variable taken into consideration in this study was the students' English level which was tested at the beginning of the semester by using a skills-based exam. In order to explore the relationship between English level defined by the CEFR (A1, A2 and B1) and the learners' level of autonomy, One-Way ANOVA analyses were performed.

Table 7

English Level and Learner Autonomy

\begin{tabular}{lccccc}
\hline Learner Autonomy & Sum of Squares & df & Mean Square & F & Sig. \\
\hline Between Groups & 189.674 & 2 & 94.837 & .024 & .976 \\
Within Groups & 1027268.356 & 264 & 3891.168 & & \\
Total & 1027458.030 & 266 & & & \\
\hline
\end{tabular}

As presented in Table 7, like age and length of English education, English level did not seem to be a significant variable for autonomy; nonetheless, as the study was conducted in the middle of the semester, the level differences that could be easily observed at the beginning of the year might have disappeared when this study was conducted.

\section{The Relationship between Learner Autonomy and Academic Performance}

The participants' LAP-SF scores and GPA were analysed through a Pearson Correlation Coefficient analysis to find out whether there was a relationship between the individuals' level of autonomy as learners and their academic success in terms of language proficiency. Pearson Correlation Coefficient is a measure that determines the linear relationship between two variables and its values can range from -1 to +1 . Values closer to 1 indicate a closer relationship between two variables, while values closer to 0 indicate a weak correlation (Mackenzie \& Knipe, 2006).

Table 8

Correlation between Learner Autonomy and Academic Performance

\begin{tabular}{llcc}
\hline & & GPA & Autonomy \\
\hline \multirow{3}{*}{ GPA } & Pearson Correlation & 1 & $.243^{* * *}$ \\
& Sig. (2-tailed) & .000 & 267 \\
\hline \multirow{2}{*}{ Autonomy } & $\mathrm{N}$ & 267 & $.243^{* * *}$ \\
& Pearson Correlation & .000 & 1 \\
& Sig. (2-tailed) & 267 & 267 \\
\hline
\end{tabular}

Note: $* *$ Correlation is significant at the 0.01 level (2-tailed).

As shown in Table 8, there was a positive correlation between the individuals' level of autonomy as learners and their academic success $(r=.243, \mathrm{p}<.01)$. This relationship reveals that the more autonomous learners are, the more successful they become in the process of language learning. 


\section{Discussion}

Regarding the first research question "What is the average level of autonomy of Turkish EFL learners at the tertiary level?", the data revealed that more than half of the Turkish university students in the study were highly autonomous and none of the participants fell into the category of low autonomy. Unlike this finding, previous studies conducted in Turkey at the beginning of the 2000s indicated that a traditional approach was adopted by teachers and thus students did not show many autonomous behaviours (Sert, 2006; Yumuk, 2002). However, during the 2010s, there have been some promising changes in Turkish educational policy, such as introducing the European Language Portfolio into the educational system and increasing the number of language courses. Accordingly, more recent studies signal a different tendency as students seem to have a more positive attitude towards autonomy and they are willing to take some responsibility for their own learning process (Dokuz, 2009; Olur, 2013; Ünal et al., 2017). In line with the findings of recent studies, the present study also revealed that Turkish students are becoming more willing to take responsibility for their own learning. Thus, we can suggest that if teachers and the curriculum support learners' autonomous behaviours, they tend to show more autonomy.

In relation to the second research question concerning whether there is a statistically significant relationship between some personal factors and the learners' level of autonomy, it was found that gender was the only variable that revealed a significant relationship with learner autonomy. This finding is in line with the findings of previous studies (Boyno, 2011; Lowe, 2009; Varol \& Yllmaz, 2010; Zhao \& Chen, 2014). One possible reason for this difference between genders may stem from females' tendency to mature earlier than males both physically and psychologically. Another possible reason might be the cultural values that impose more responsibility on females. In addition, the fact that females outperformed males is not a surprising finding as Green and Oxford (1995) put forward that females use more learning strategies and thus they are more successful language learners. Similarly, females seem to be more open to trying new things and are better at self-studying and doing non-compulsory assignments, which makes them more autonomous in and outside the classroom (Varol \& Yılmaz, 2010). According to Turkish child-raising customs, females are encouraged to take more responsibility than males. As learner autonomy is closely related to taking responsibility, it is not surprising to see that females have higher autonomy scores than males.

Regarding the other variables, which were age, length of English education, and English level, none of them showed a significant relationship with learner autonomy. There could be several reasons for these results. In terms of age, 247 out of the 267 total participants were between 18 and 20 . This meant that $95 \%$ of the participants fell in the same age group. Since the participants' ages were very close, it might have affected the results. In other words, a large group of participants in such a limited age range might make it difficult to reach a comprehensible conclusion. Consequently, it was not surprising that age did not reveal any relationship with learner autonomy.

The length of English education was also included in this research study to see whether there is a relationship between length of English education and autonomy. However, it was found that there was not a significant relationship between the length of English education and learner autonomy. Unlike Tuo and Xia (2017) who found a positive correlation between learner autonomy and the length of English education, learning experience or length of education was not found to be an important factor for learner autonomy in the present study. Tuo and Xia (2017) suggest that the positive relationship between the length of education and autonomy is a result of curriculum reform in Chinese higher education. In China, more emphasis has been given to promoting autonomous learning behaviour by using multimedia facilities; however, there is no deliberate attempt in the Turkish higher education curriculum and this might be the underlying reason why length of education was not found to be an important factor for learner autonomy. Moreover, the demographic information revealed that the majority of the participants had been learning English for nine or more years (up to 15). The fact that most of the participants had been studying English for many years might have prevented the detection of differences related to this variable. Most Turkish EFL learners have been learning English for a long time and this education has generally been compulsory since they started fourth grade of elementary school. Hence, the variable of length of English education was expected to have a neutral effect.

Regarding the participants' English level and autonomy, the data analysis revealed that there was not a significant relationship between these two variables. In the sample group, based on the test that was administered at the beginning of the semester, there were $130 \mathrm{~A} 1$ level, $63 \mathrm{~A} 2$ level, and $74 \mathrm{~B} 1$ level students according to the CEFR. 
Both A1 and A2 level students were expected to reach a B1 level by the end of the term. On the other hand, the aim of the B1 level students was to reach a B2 level. This study was conducted just before the final test. In other words, more than $70 \%$ of the participants reached the same level, which was a B1 level. As the majority of the participants were at the same English level, it might have not been possible to see the relationship between the English level and learner autonomy in this study. Another possible reason for not finding any differences is the fact that English level groups were established at the beginning of the fall term; however, learners' autonomy level was measured in the middle of the spring term. Therefore, some of the learners' English levels might have improved as a result of becoming more autonomous over time.

The third research question put forward the main concern of this study, which was to explore whether there is a relationship between learner autonomy and language proficiency in Turkish students at the tertiary level. In order to reach this aim, the data gathered from questionnaires and the students' GPA were analysed using a Pearson Correlation Coefficient analysis. A positive but weak correlation between learner autonomy and academic success was found. In line with this finding, previous research studies (Alrabai, 2017; Dafei, 2007; Ghorbandordinejad \& Ahmadabad, 2016; Lowe, 2009; Myartawan et al., 2013; Tilfarlioglu \& Ciftci, 2011; Tuo \& Xia, 2017; Yen \& Liu, 2009) conducted in various countries suggest a positive correlation between these two constructs. In the literature, there is a widespread belief that more autonomy positively influences efficient learning, which facilitates the achievement of higher levels of language proficiency (Dafei, 2007; Ghorbandordinejad \& Ahmadabad, 2016). Therefore, it can be concluded that learner autonomy and academic success mutually reinforce each other. In short, it is possible to say that learner autonomy is related to language success. A student with a higher level of autonomy tends to achieve high academic scores; on the other hand, those with a low degree of learner autonomy are likely to achieve low scores. This finding emphasizes the importance of learner autonomy in successful language learning processes.

There were some restrictions in this study. First, the sample consisted of students enrolled at a single state university. Therefore, the results may not be generalizable to all university students throughout the country. Secondly, although the instrument sought to minimize these issues, it is possible that question ambiguity, personal bias, and a lack of knowledge by the respondents were present. Furthermore, it should be taken into consideration that this was not a longitudinal study; thus, the overall stability of the study may be subject to question. Another limitation is related to the timeline of the study. The English level groups (A1, A2, and B1) were formed at the beginning of the fall semester. The study was conducted during the spring term and students' GPAs and their autonomy scores belonged to the second term. Therefore, some students' levels might have changed over time or they might be more successful than others due to their higher autonomy. Lastly, participants' age intervals were limited. The majority (95\%) were between 18 and 20 years old. Hence, the results may not be generalizable for younger or older groups.

\section{Conclusion}

In the current study, a link was found between autonomy and learners' language learning achievements. This finding emphasizes that learners who take responsibility for their own learning tend to be more successful in language learning. Thus, the concept of autonomy is significant for all language learners and teachers. What really matters is to understand the role of autonomy in language learning and find ways to foster it, such as through pair work, group work, computer-assisted language learning, distance learning, out-of-class learning, self-instruction, and self-reflection. We believe it is crucial to create opportunities to promote learner autonomy by using awareness-raising activities, fostering self-assessment, and engaging learners in cooperative work. However, it may not be realistic to expect students to take responsibility for their learning in a short time and teachers, as the authority in the classroom, might not be ready to hand over responsibility to learners. Hence, principles of autonomy should be included in the training of both pre-service and in-service teacher education programs. In addition to learners and teachers, the curriculum, assessment tools, and books need to be reorganized in accordance with the principles of autonomy.

To date, the relationship between autonomy and language learning has largely been explored at the theoretical level and lacks empirical support. There is a need for more comprehensive and experimental studies that focus on observing autonomy in the classrooms by including teachers' and students' concerns and attitudes. 


\section{Conflict of Interest}

The authors declare that they have no conflict of interest.

\section{References}

Alrabai, F. (2017). Exploring the unknown: The autonomy of Saudi EFL learners. English Language Teaching, 10(5), 222-233. https://doi.org/10.5539/elt.v10n5p222

Balçıkanlı, C. (2010). Learner autonomy in language learning: Student teachers' beliefs. Australian Journal of Teacher Education, 35(1), 90-103. https://doi.org/10.14221/ajte.2010v35n1.8

Benson, P. (2001). Teaching and researching autonomy in language learning. London, UK: Longman.

Benson, P. (2010). Measuring autonomy: Should we put our ability to the test? In A. Paran \& L. Sercu (Eds.), Testing the untestable in language education (pp. 120-139). Bristol, UK: Multilingual Matters.

Benson, P., \& Huang, J. (2008). Autonomy in the transition from foreign language learning to foreign language teaching. DELTA: Documentação de Estudos em Lingüística Teórica e Aplicada, 24(Special Issue), 421-439. https://doi.org/10.1590/S0102-44502008000300003

Bhattacharya, A., \& Chauhan, K. (2010). Augmenting learner autonomy through blogging. ELT Journal, 64(4), 376-384. https://doi.org/10.1093/elt/ccq002

Borg, S., \& Al-Busaidi, S. (2012). Learner autonomy: English language teachers' beliefs and practices. ELT Journal, 12(7), 1-45. Retrieved from https://academic.oup.com/eltj/article-abstract/64/4/376/389744

Boyno, M. (2011). An analysis of the factors influencing learner autonomy in the Turkish EFL context (Unpublished doctoral dissertation). University of Çukurova, Adana, Turkey.

Candy, P. C. (1991). Self-direction for lifelong learning. San Francisco, CA: Jossey- Bass.

Carr, P. (1999). The measurement of resourcefulness intentions in the adult autonomous learner (Unpublished doctoral dissertation). The George Washington University, Washington, D.C.

Chan, V. (2001). Readiness for learner autonomy: What do our learners tell us? Teaching in Higher Education, 6(4), 505-518. https://doi.org/10.1080/13562510120078045

Confessore, G. J. (2000). The learner autonomy profile: Findings of the validation study. Paper presented at the 2nd Royaumont symposium on self-learning, Parise, France.

Confessore, G. J., \& Park, E. (2004). Factor validation of the learner autonomy profile, version 3.0 and extraction of the short form. International Journal of Self-Directed Learning, 1(1), 39-58.

Cotterall, S. (2000). Promoting learner autonomy through the curriculum: Principles for designing language courses. ELT Journal, 54(2), 109-117. Retrieved from https://academic.oup.com/eltj/article/54/2/109/413633

Cummins, J. (2008). BICS and CALP: Empirical and theoretical status of the distinction. In N. H. Hornberger \& B. Street (Eds.), Encyclopedia of language and education (pp. 71-83). New York, NY: Springer Science.

Dafei, D. (2007). An exploration of the relationship between learner autonomy and English proficiency. Asian EFL Journal, 24(4), 24-34. Retrieved from http://www.asian-efl-journal.com/pta_Nov_07_ dd.pdf?origin=publication_deta

Dam, L. (2003). Developing learner autonomy: The teacher's responsibility. In D. Little, J. Ridley \& E. Ushioda (Eds.), Learner autonomy in foreign language classrooms: Teacher, learner, curriculum and assessment (pp. 135146). Dublin, Ireland: Authentik.

Dam, L., \& Legenhausen, L. (2010). Learners reflecting on learning: Evaluation versus testing in autonomous language learning. In A. Paran \& L. Sercu (Eds.), Testing the untestable in language education (pp. 120-139). Bristol, UK: Multilingual Matters.

Derrick,M.G.(2001). The measurement of intentions to exhibit persistence in adult autonomous learners (Unpublished doctoral dissertation). The George Washington University, Washington, D.C. Retrieved from https://search. proquest.com/pqdtglobal/docview/276280161/BB2C5CCE7F304A2FPQ/2?accountid=11054

Dokuz, Ö. (2009). An investigation into tertiary level Turkish EFL students' awareness level of learner autonomy and their attitudes (Unpublished master's thesis). University of Karadeniz, Trabzon.

Dornyei, Z., \& Ryan, S. (2015). The psychology of the language learner revisited. New York, NY: Routledge. https:// doi.org/10.4324/9781315779553

Ertürk, N. O. (2016, April). Language learner autonomy: Is it really possible? Procedia - Social and Behavioral Sciences, 232, 650-654. https://doi.org/10.1016/j.sbspro.2016.10.089 
Gardner, R. C., \& MacIntyre, P.D. (1993). A student's contributions to second-language learning. Part II: Affective variables. Language Teaching, 26(1), 1-11. https://doi.org/10.1017/S0261444800000045

Ghorbandordinejad, F., \& Ahmadabad, R. M. (2016). Examination of the relationship between autonomy and English achievement as mediated by foreign language classroom anxiety. Journal of Psycholinguistic Research, 45(3), 739-752. https://doi.org/10.1007/s10936-015-9371-5

Green, J. M., \& Oxford, R. (1995). A closer look at learning strategies, L2 proficiency, and gender. TESOL Quarterly, 29(2), 261-297. Retrieved from https://www.jstor.org/stable/3587625

Ho, J. H. (1998). Sources of second language anxiety and the benefits of instructor intervention. Kwa Kang Journal of TEFL, 4(1), 73-104. https://doi.org/10.6362/HKJTEFL.199805.0073

Holec, H. (1981). Autonomy in foreign language learning. Oxford, UK: Pergamon.

İmre, N. (2015). An investigation into relationship between degree of learning autonomy, academic and social variables (Unpublished master's thesis). University of Bahçeşehir, İstanbul, Turkey.

Lamb, T. (2010). Assessment of autonomy or assessment for autonomy? Evaluating learner autonomy for formative purposes. In A. Paran \& L. Sercu (Eds.), Testing the untestable in language education (pp. 98-119). Bristol, UK: Multilingual Matters.

Lee, L. (2016). Autonomous learning through task-based instruction in fully online language courses. Language Learning \& Technology, 20(2), 81-97. Retrieved from http://lt.msu.edu/issues/june2016/lee.pdf

Little, D. (1991). Autonomy: Definitions, issues and problems. Dublin, Ireland: Authentik.

Little, D. (1995). Learning as dialogue: The dependence of learner autonomy on teacher autonomy. System, 23(2), 175-181. Retrieved from https://www.sciencedirect.com/science/article/pii/0346251X95000066

Little, D. (1999). Learner autonomy is more than a western cultural construct. In S. Cotterall \& D. Crabbe (Eds.), Learner autonomy in language learning: Defining the field and effecting change (pp. 11-18). Frankfurt, Germany: Peter Lang.

Little, D. (2002). The European Language Portfolio: Structure, origins, implementation and challenges. Language Teaching, 35(3), 182-189. https://doi.org/10.1017/S0261444802001805

Little, D. (2003). Learner autonomy and second/foreign language learning. Guide to Good Practice. Retrieved from https://www.llas.ac.uk/resources/gpg/1409

Little, D. (2007). Language learner autonomy: Some fundamental considerations revisited. Innovation in Language Learning and Teaching, 1(1), 14-29. https://doi.org/10.2167/illt040.0

Little, D. (2017). Three Versions of Learner Autonomy and their Implications for English-Medium Degree Programmes. In R. Breeze \& C. S. Guinda (Eds.), Essential competencies for English-medium university teaching (pp. 145-157). Basel, Switzerland: Springer International Publishing.

Liu, H. J. (2012). Understanding EFL undergraduate anxiety in relation to motivation, autonomy, and language proficiency. Electronic Journal of Foreign Language Teaching, 9(1), 123-129. Retrieved from http://citeseerx. ist.psu.edu/viewdoc/download?doi=10.1.1.454.4010\&rep=rep1 \&type=pdf

Lowe, C. (2009). A correlational study of the relationship between learner autonomy and academic performance (Unpublished master's thesis). The George Washington University, Washington, D.C.

Mackenzie, N., \& Knipe, S. (2006). Research dilemmas: Paradigms, methods and methodology. Issues in Educational Research, 16(2), 193-205. Retrieved from http://www.iier.org.au/iier16/mackenzie.html

Meyer, D. A. (2001). The measurement of intentional behavior as a prerequisite to autonomous learning (Unpublished doctoral dissertation). The George Washington University, Washington, D.C.

Myartawan, I., Latief, M. A., \& Suharmanto, S. (2013). The correlation between learner autonomy and English proficiency of Indonesian EFL college learners. TEFLIN Journal: A publication on the teaching and learning of English, 24(1), 63-81. Retrieved from http://www.teflin.org/journal/index.php/journal/article/view/155

Naeeini, S. K., Riazi,A., \& Salehi, H. (2012). The role of social factors in Iranian university students' predispositions towards autonomous language learning. Advances in Language and Literary Studies, 3(2), 41-51. Retrieved from http://journals.aiac.org.au/index.php/alls/article/view/53

Ng, S. F., Confessore, G. J., \& Abdullah, M. (2012). Learner autonomy coaching: enhancing learning and academic success. International Journal of Mentoring and Coaching in Education, 1(3), 191-204. https://doi. org/10.1108/20466851211279457

Ng, S. F., Confessore, G. J., Yusoff, Z., Abdul Aziz, N. A., \& Lajis, N. M. (2011). Learner autonomy and academic performance among undergraduate students. International Journal of Social Sciences \& Education, 1(4), 669679.

Olur, H. (2013). Awareness of high school learners of learner autonomy (Unpublished master's thesis). University of Atatürk, Erzurum, Turkey.

Oxford, R. L. (1989). Use of language learning strategies: A synthesis of studies with implications for strategy 
training. System, 17(2), 235-247. https://doi.org/10.1016/0346-251X(89)90036-5

Oxford, R. L. (1999). Relationships between second language learning strategies and language proficiency in the context of learner autonomy and self-regulation. Revista Canaria de Estudios Ingleses, 38(1), 108-26.

Ponton, M. (1999). The measurement of an adult's intention to exhibit personal initiative in autonomous learning (Unpublished doctoral dissertation). The George Washington University, Washington, D.C.

Reinders, H. (2006). Supporting self-directed learning through an electronic learning environment. In T. Lamb \& H. Reinders (Eds.) Supporting independent learning: Issues and interventions (pp. 219-238). Frankfurt, Germany: Peter Lang.

Reinders, H., \& Balçıkanll, C. (2011). Do classroom textbooks encourage learner autonomy? Novitas-ROYAL (Research on Youth and Language), 5(2), 265-272. Retrieved from http://www.novitasroyal.org/Vol_5_2/ ReindersH_BalcikanliC.pdf

Sanprasert, N. (2010). The application of a course management system to enhance autonomy in learning English as a foreign language. System, 38(1), 109-123. https://doi.org/10.1016/j.system.2009.12.010

Sert, N. (2006). EFL student teachers' learning autonomy. Asian EFL Journal, 8(2), 180-201.

Solórzano, R. W. (2008). High stakes testing: Issues, implications, and remedies for English language learners. Review of Educational Research, 78(2), 260-329. https://doi.org/10.3102/0034654308317845

Thomson, C.K. (1996). Self-assessment in self-directed learning: Issues of learner diversity. In Pemberton, R., Li, E. S., Or, W. W., \& Pierson, H. D. (Eds.), Taking control: Autonomy in language learning (pp. 77-91). Hong Kong, China: Hong Kong University Press.

Tilfarlioglu, F. Y., \& Ciftci, F. S. (2011). Supporting self-efficacy and learner autonomy in relation to academic success in EFL classrooms (A case study). Theory \& Practice in Language Studies, 1(10), 1284-1294. https:// doi.org/10.4304/tpls.1.10.1284-1294

Tuo, Y., \& Xia, Z. (2017, April). A study on learner autonomy among ethnic preparatory students. Paper presented at the 3rd international conference on education and social development, Shaanxi, China.

Ünal, S., Çeliköz, N., \& Sarı, İ. (2017). EFL proficiency in language learning and learner autonomy perceptions of Turkish learners. Journal of Education and Practice, 8(11), 117-122.

Üstünlüoğlu, E. (2009). Autonomy in language learning: Do students take responsibility for their learning? Journal of Theory \& Practice in Education (JTPE), 5(2), 148-169. Retrieved from http://eku.comu.edu.tr/index/5/2/e_ ustunluoglu.pdf

Varol, B., \& Yilmaz, S. (2010). Similarities and differences between female and male learners: Inside and outside class autonomous language learning activities. Procedia-Social and Behavioral Sciences, 3, 237-244. https:// doi.org/10.1016/j.sbspro.2010.07.038

Yen, C. J., \& Liu, S. (2009). Learner autonomy as a predictor of course success and final grades in community college online courses. Journal of Educational Computing Research, 41(3), 347-367. https://doi.org/10.2190/ EC.41.3.e

York, T. T., Gibson, C., \& Rankin, S. (2015). Defining and measuring academic success. Practical Assessment, Research \& Evaluation, 20(5), 1-20. Retrieved from http://pareonline.net/getvn.asp?v=20\&n=5

Yumuk, A. (2002). Letting go of control to the learners: the role of the Internet in promoting a more autonomous view of learning in an academic translation course. Educational Research, 44(2), 141-156. https://doi. org/10.1080/00131880210135278

Zarei, A., \& Zarei, N. (2015). On the effect of language proficiency on learners' autonomy and motivation. Journal of English Language and Literature, 3(2), 263-270. Retrieved from http://www.ikiu.ac.ir/public-files/profiles/ items/090ad_1428209089.pdf

Zhao, X., \& Chen, W. (2014). Correlation between learning motivation and learner autonomy for non-English majors. World Transactions on Engineering \& Technology Education, 12(3), 374-379. Retrieved from http:// www.wiete.com.au/journals/WTE\&TE/Pages/Vol.12,\%20No.3\%20(2014)/08-Zhao-X.pdf 